\title{
Criminología y racismo: a propósito de las políticas necro-criminales a los inmigrantes
}

Criminology and Racism: About Necro-criminal Policies on Immigrants

Criminologia e racismo: sobre as políticas necrocriminais aos imigrantes

Criminologie et racisme: à propos des politiques nécro-criminelles contre les immigrés

Gabriela L. Gusis ${ }^{1}$ | Universidad Nacional de La Plata

Revista Derechos en Acción

Año 3/No 9 primavera 2018, 266-289

DOl: https://doi.org/10.24215/25251678e221

ORCID: https://orcid.org/0000-0003-3067-7998

Recibido: 17/08/2018

Recibido con modificaciones: 28/09/2018

Aprobado: 19/11/2018

Resumen: Este trabajo pretende preguntarse sobre la relación entre la inmigración, la criminología y el racismo. Cuál es la relación la criminología o la sociología-penal desde una perspectiva histórico- genealógica y cómo se han gestado algunas ideas/saberes que parecieran ser hoy una cuestión puesta de manifiesto por la política criminal global en torno a los migrantes. Qué rol fundamental juega el racismo en los saberes-poderes que continúan presentando a personas con más 0 menos derechos de acuerdo a su antojo, a pesar de tener hoy de manera indiscutida un modelo de estado constitucional de derechos y un enorme bagaje proveniente del derecho internacional de los derechos humanos

\footnotetext{
1 Profesora de Derecho penal y Criminología UBA-UNLP-UNDAV. Secretaria del Departamento de Derecho Penal y Criminología de la Facultad de Derecho de la Universidad Nacional de Buenos Aires, Argentina.
} 
que aspiran a la universalización de los derechos fundamentales y al reconocimiento de todo ser humano como tal.

Palabras claves: Criminología; racismo; inmigración.

Abstract: This paper seeks to ask about the relationship between immigration, criminology and racism. What is the relationship between criminology or criminal sociology from a historical-genealogical perspective, and how have some ideas/knowledge been generated that seem to be a question that has been raised today by the global criminal policy around migrants. What fundamental role does racism play in the knowledge-powers that continue to present people with more or less rights according to their whim, in spite of having today in an indisputable way a model of constitutional state of rights and an enormous baggage coming from the international law of human rights that aspire to the universalization of fundamental rights and to the recognition of every human being as such.

Keywords: Criminology; racism; immigration.

Resumo: Este artigo pretende perguntar-se sobre a relação entre imigração, criminologia e racismo. Qual é a relação entre criminologia ou sociologia criminal desde uma perspectiva histórico-genealógica e como foram gestadas algumas idéias / conhecimentos que parecem ser hoje uma questão destacada pela política criminal global ao redor dos migrantes? Qual é o papel fundamental do racismo nos conhecimento-poderes que continuam apresentando as pessoas com mais ou menos direitos de acordo com a sua vontade, apesar de ter hoje maneira indiscutível um modelo de estado constitucional de direitos e uma enorme bagagem vindo do direito internacional dos direitos humanos que aspiram à universalização dos direitos fundamentais e ao reconhecimento de todo ser humano como tal.

Palavras Chaves: criminologia; racismo; imigração.

Résumé: Cet article vise à poser des questions sur les relations entre immigration, criminologie et racisme. On se demande quelle est la relation entre la criminologie et la sociologie criminelle dans une perspective généalogique-historique et comment certaines idées et connaissances ont été développées et sont aujourd'hui révélées par la politique criminelle mondiale en matière d'immigration. Quel est le rôle fondamental du 
racisme dans les discours qui continuent de présenter aux gens moins de droits que d'autres, malgré le modèle incontesté de l'état constitutionnel des droits. Ainsi qu'un vaste droit international relatif aux droits de I'homme qui aspire à l'universalisation des droits fondamentaux et à la reconnaissance de tout être humain en tant que tel.

Mot-clés: Criminologie; le racisme,l'immigration

\section{Presentación}

Este trabajo pretende preguntarse sobre la relación entre la inmigración, la criminología y el racismo.

Cuál es la relación la criminología o la sociología-penal desde una perspectiva histórico- genealógica y cómo se han gestado algunas ideas/saberes que parecieran ser hoy una cuestión puesta de manifiesto por la política criminal global en torno a los migrantes.

Qué rol fundamental juega el racismo en los saberespoderes que continúan presentando a personas con más o menos derechos de acuerdo a su antojo, a pesar de tener hoy de manera indiscutida un modelo de estado constitucional de derechos y un enorme bagaje proveniente del derecho internacional de los derechos humanos que aspiran a la universalización de los derechos fundamentales y al reconocimiento de todo ser humano como tal.

A simple vista se observan algunas tensiones que presenta la investigación:

En el plano de la teoría política del estado, se muestran como dicotomías entre el Estado de policía y el estado constitucional de derechos.

En el plano de las relaciones de poder, en el poder del estado en tensión con la libertad y los derechos humanos de las personas.

En el plano penal-criminológico, sin embargo, estas tensiones se expresan en la más amplia o restringida admisión de 
trato punitivo a seres humanos a los que se les priva de la condición de personas -en mayor o menor medida-.

\section{Advertencia}

Sería sumamente pretencioso afirmar que estos problemas podrán ser abarcados completamente en la ponencia.

Cada uno de los tópicos, a saber: migración, criminología y racismo, han sido y continúan siendo trabajados en profundidad por sendos autores de antaño y contemporáneos.

Las posibilidades infinitas me obligan, por ello, a restringir el análisis al menos a ciertos ejes que nos darán una aproximación a la cuestión.

Sin embargo, cabe advertir que algunos autores resultan centrales para abordar la cuestión. Entre ellos, son referencia absoluta Michel Foucault, en particular a partir de los lineamientos abordados en la serie de conferencias "defender la sociedad" 2 que se publicó también con el nombre de "Genealogía del racismo" en Argentina3 ; Achile Mbembé ${ }^{4}$ y Frantz Fanon", desde una perspectiva crítica negra; Giorgio Agamben $^{6}$ quien nos aporta conceptos fundamentales que relacionan el derecho, la excepción y el trato a los seres humanos, René Girard ${ }^{7}$ quien nos permite integrar en el análisis aquellos

2 Foucault, M. (2003). Hay que defender la sociedad. Madrid: Akal.

3 Foucault, M. (1996). Genealogía del racismo. La Plata: Altamira.

4 Mbembe, A. (2016), Crítica de la razón negra. Ensayo sobre el racismo contemporáneo. Barcelona: NED Ediciones. Mbembe, A. (2011), Necropolítica. Barcelona: Melusina. Mbembe, A. (2012), «Necropolítica, una revisión crítica», en Chávez, E. y Ježik, E. Estética y Violencia: necropolítica, militarización y vidas Iloradas. México D.F.: Museo.

5 Fanon, F. (1961), Los condenados de la tierra. Fanon, F. (1971), Piel negra máscaras blancas. Bs. As: Abraxas. Fanon, F (1964/5), Por la revolución africana. Bs. As/México: Fondo de cultura económica.

6 Agamben, G. (1998), Homo Sacer. El poder soberano y la nuda vida. Valencia: Pre-Textos. Agamben, G. (2004), Estado de excepción. Valencia: Pre-Textos. Agamben, G. (2003), Homo Sacer. El poder del soberano y la nuda vida. Valencia: Pre-textos.

7 Girard, R. (1972), La violencia y lo sagrado. Barcelona: Anagrama. 
mecanismos mediante los cuales se produce la sacralización del mito y la conversión de víctima en victimario; Lola Aniyar de Castro $^{8}$ y Raúl Zaffaroni ${ }^{9}$, desde la perspectiva de análisis crítico criminológico-latinoamericano ${ }^{10}$; a quien no pueden dejar de sumarse también desde una perspectiva crítica y con una mirada integral del saber penal al maestro Alessandro Baratta ${ }^{11}$, y particularmente desde el análisis de la filosofía ius humanista a Luigi Ferrajoli ${ }^{12}$.

\section{Las relaciones indisolubles entre la criminología y el derecho penal}

Desde la criminología demonológica (inquisitorial), que encontró la justificación de la persecución de Satán ${ }^{13}$ para oprimir y controlar de modo verticalizante ${ }^{14}$, en particular, a las mujeres y las culturas diversas, hasta la actualidad, se observan cauces que -como hemos advertido- se trazan entre la soberanía, el poder y la libertad.

Las tensiones se manifiestan como pulsiones de poder estatal en detrimento de los seres humanos, que a pesar de los límites impuestos al poder punitivo en los siglos XVII y XVIII,

8 Aniyar de Casto, L. (2010), Criminología de los Derechos Humanos -criminología axiológica como política criminal-.Bs. As: Ed. Del puerto. Aniyar de Castro, L.; Codino (2013), R., Manual de criminología sociopolítica. Bs. As: Ediar.

9 Zaffaroni, E. R. (2006) El enemigo en el derecho penal. Bs. As: EDIAR. Zaffaroni, E. R (2013), La cuestión Criminal. Bs. As.: Ed. Planeta. $5^{a}$ edición. Zaffaroni, E. R., La Palabra de los muertos (2012), Bs. As.: EDIAR. Zaffaroni, E. R. (2009) Crímenes de masa. Bs. As.: Madres. Zaffaroni, E. R (2016), Muertes anunciadas. Avellaneda: UNDAV.

10 Nos posicionamos aquí en la necesidad de que la criminología sea preventiva de masacres, y desde esa óptica abonamos a la criminología de (o para) los derechos humanos (Lola Aniyar de Castro: 2010) como complementaria de la criminología cautelar (E. Raúl Zaffaroni: 2010).

11 Baratta, A (1975), Criminologia liberale e ideología della difesa sociale, en La Questione criminale. Baratta, A (1996), Criminología crítica y crítica del derecho penal. Bs. As/Mexico: Siglo XXI.

12 Ferrajoli, L. (1999) Derecho y Razón. Madrid: Trotta.

13 De Satan al Derecho Penal Cool...

14 y colonizante. 
continúa en la realidad afirmando el control sobre los cuerpos a través de los estados, aún en la era de la globalización.

Estas resistencias, desde una perspectiva dialéctica se manifiestan en el plano de la teoría del estado en los vaivenes que se producen entre el estado de derecho y el estado de policía, que traducidos en el campo penal se reflejan en la más amplia o restringida admisión del trato punitivo a seres humanos privados de la condición de personas.

El trato diferenciado provoca una contradicción entre la doctrina penal, por una parte, y la teoría política del estado constitucional de derecho y del derecho internacional de los derechos humanos por la otra, debido a que la última no admite ni siquiera en una situación bélica clara, resignar los derechos que por tal posee todo ser humano.

Afirmar lo contrario implicaría abandonar el principio del estado de derecho y pasar al de policía, que se deslizaría muy rápido hacia el estado absoluto.

En las últimas décadas se ha producido una transformación regresiva bastante notoria en el campo de la llamada política criminal o, más precisamente, política penal, pues del debate entre políticas abolicionistas y reduccionistas se pasó, casi sin solución de continuidad, a debatir la expansión del poder punitivo, con lo cual el tema del enemigo de la sociedad pasó a primer plano de discusión.

Quizá hasta cierto punto los teóricos cayeron en la negación del fenómeno de represivización de las legislaciones penales sancionadas con motivo o pretexto de emergencias ${ }^{15}$, hasta que la realidad legislativa alcanzó un punto que impedía todo mecanismo de huída; pero cierto es que la invocación de emergencias justificantes de estados de excepción no son recientes. Tan sólo tomar la etapa posterior a la segunda guerra mundial, hace más de cuatro décadas que se vienen sancionando en Europa y Estados Unidos estas leyes, que se ordinarizan -convirtiéndose en la

15 Sobre el concepto de emergencia, por todos, Moccia, S. (2000), La perenne emergenza, Napoli. 
excepción perpetua- y que fueron superadas largamente por la legislación de seguridad latinoamericana.

Se ha señalado que las características de este avance contra el tradicional derecho penal liberal o de garantías consistirían en la anticipación de las barreras de punición (alcanzando a los actos preparatorios), la desproporción en las consecuencias jurídicas (penas como medidas de contención sin proporción con la lesión realmente inferida), el marcado debilitamiento de las garantías procesales y la identificación de los destinatarios mediante un fuerte giro al derecho penal de autor (Zaffaroni: 2006).

La evocación, en general de la criminología o sociología del castigo, en este aspecto, ha presentado fuertes momentos legitimantes fuertes del poder punitivo pasando desde la primer criminología inquisitorial colonizante y verticalizante, a la criminología positivista-peligrosista del siglo XIX, momento centrado en el poder planetario del neocolonialismo, llegando al actual momento de poder mundial tardo-colonialista (globalizado) basado en el sistema de mercado económico-financiero con una criminología justificadora del poder punitivo que no dista en esencia de los primeros modelos hegemonizantes pero atravesados por la criminología mediática que refuerza y sostiene los estereotipos racistas de antaño y actuales.

Existe un vaivén de políticas criminales. Éstas derivan no sólo del refinamiento del pensamiento político, sino también de presiones sociales regresivas, como la nueva criminalización de inmigrantes, que han sido convertidos en un nuevo chivo expiatorio dentro de una precaria e interesada globalización.

Zaffaroni advierte que el poder se planetarizó y amenaza con una dictadura global; el potencial tecnológico de control informático puede acabar con toda intimidad; el uso de ese potencial controlador no está limitado ni existe forma de limitarlo a investigar sólo hechos determinados; las condiciones del planeta se deterioran rápidamente y la vida misma se halla amenazada. Se opera un enorme proceso de concentración de capital que procura mayor renta sin detenerse ante ningún obstáculo no ya ético, sino incluso físico; los estados nacionales 
son débiles e incapaces de proveer reformas estructurales; la comunicación masiva, de formidable poder técnico, está lanzada a una propaganda völkisch y vindicativa sin precedentes; la capacidad técnica de destrucción puede arrasar la vida; se desatan guerras unilateralmente con fines claramente económicos; y, para colmo, el poder planetario fabrica enemigos y emergencias -con los consiguientes estados de excepción- en serie y a alta velocidad (Zaffaroni:2006).

La profesora Aniyar de Castro ya enseñaba que el crecimiento del racismo en Europa y en Estados Unidos, en gran parte debido a las incontenibles migraciones producto de la mencionada globalización, se manifiestan claramente tanto en el tipo de la investigación que se hace en las criminologías de esas regiones, como en la fenomenología, del control formal. Hasta se ha acuñado un término propio para el fenómeno de la inmigración criminalizada: "Crimmigration"16.

El concepto de "enemigo" es más grave en el terreno criminológico, que cuando se considera la expropiación de las garantías en alguna doctrina penal y ya en muchas legislaciones tanto americanas como europeas. Los Patriot Acts posteriores a la destrucción de las Torres Gemelas son un ejemplo, pero tanto en España como en Francia, Italia e Inglaterra se han ido cerrado las tenazas sobre el extranjero como nuevo enemigo, y el concepto de "frontera" de origen típicamente militar, ha comenzado a tener nuevos sentidos en nuestra política criminal (Aniyar de Castro: 2010).

El Sistema Penal del "otro" es el que pertenece a las subculturas de quienes forman parte de grupos étnicos o nacionales diferentes a los de la cultura e instituciones dominantes: algunos grupos de inmigrantes, africanos o de otros países, y los religiosos que practican procedimientos no aceptados en occidente son un ejemplo de ello $^{17}$.

\footnotetext{
16 Aniyar de Castro, L., quien advierte además sobre las trampas que imbrica el término "ilegal" para designar al migrante, lo que lo estereotipa y estigmatiza conceptual y socialmente.

17 Las teorías de las subculturas ponen de resalto que no sólo existe, en efecto, un único sistema oficial de valores, sino también una serie de subsistemas que se transmiten a los
} 
Esto puede extrapolarse sin mayores dificultades al control penal subterráneo (lesiones, torturas, detenciones ilegales, sentencias condenatorias o más severas), donde dicha expropiación se realiza sin necesidad de mayores teorizaciones, pues es generalmente impune.

Este control penal, generalmente sostenido por un cierto desinterés, cuando no entusiasta apoyo, por parte de la colectividad se alimenta de estereotipos y de elementos emocionales transmitidos y aprendidos (intolerancia, rechazo de la diferencia, un sentimiento de repulsión o simplemente incomprensión, la que generalmente es también ignorancia y rusticidad) ${ }^{18}$.

Detrás de esas conductas, no puede dejar de observarse la negación de la víctima en punto a la desvalorización de su condición de persona humana, que pone de manifiesto las ya conocidas técnicas de neutralización que traducidas al plano del negacionismo fueron exquisitamente desarrolladas por Cohen $(2005)^{19}$. La no- persona no tiene entidad ética, es un excluido de la comunidad y eso es lo que permite su sacrificio.

En el plano penal, las políticas justificadoras del poder se han presentado o fueron definidas a través de las tesis de la defensa social, sea en sus vertientes positivas o funcionalistas, lo que también se ha evidenciado en la fuerte avanzada punitivista beligerante.

Los modelos legitimantes del poder punitivo han sostenido la "razón de estado" en detrimento de los derechos

\footnotetext{
individuos por medio de mecanismos de socialización y aprendizaje específicos a los ambientes y a los grupos sociales particulares dentro de los cuales los individuos están insertos. Por otro lado, queda fuera del poder de decisión del individuo -y por lo tanto también de su responsabilidad moral- el hecho de participar o no en una determinada subcultura y en consecuencia de aprender un determinado sistema de valores o bien determinados modelos de comportamientos desviado o de criminal por instancias que detentan el poder de definición. Las chances de resultar etiquetado, con las graves consecuencias que ello conlleva, se encuentran desigualmente distribuidas.

18 Esto es también aplicable a los crímenes de odio. Eso explicaría, a su vez, las racionalizaciones de muchas de las Ilamadas "ejecuciones extrajudiciales" afirma la autora.

19 Cohen, S. (2005), Estados de negación. Bs. As: Publicaciones UBA/British Council.
} 
fundamentales, convirtiendo al derecho penal en una "Schifoza Sciencia" en el sentido en que Francesco Carrara advirtiera siempre en su clásica obra.

No por nada Baratta advertía sobre el retraso de la ciencia jurídica respecto del pensamiento criminológico (deslegitimante/crítico), lo que lo llevaba a sostener que "ya no puede ser recuperado a través de una crítica inmanente o autocrítica situada en el interior de la ciencia jurídica" por lo que postulaba la refundación del saber penal frente a los límites de su autocomprensión desnaturalizando definitivamente postulados simplificadores del saber convencional ${ }^{20}$.

Los últimos modelos que han abordado la cuestión, en particular luego de los atentados conocidos como 11-S y 11-M, han sido aquellos que giraron en torno al derecho penal del enemigo en la versión funcionalista alemana ${ }^{21} \mathrm{o}$ bien a las propuestas de derecho penal de diferentes velocidades en las versiones de defensa social españolas ${ }^{22}$ que, en gran medida afirman que es posible establecer un derecho penal que opere de modo tradicional, colmado de garantías para aquellos que pueden ser considerados como ciudadanos y otro, u otros ajenos a la comunidad, para quienes el derecho penal pueda brindar respuestas diferenciales, con menores derechos y garantías.

El mecanismo mediante el cual se define quién ingresa a cada sistema resulta sumamente interesante si consideramos que el enemigo es aquel a quien se considera extraño, una alteridad distante pero cercana y por tal motivo también temida.

En este punto cobra relevancia la proximidad terminológica, según la RAE, de "extraño" y "extranjero". En tanto el primero se define como: 1. adj. De nación, familia o profesión distinta de la que se nombra o sobrentiende, en contraposición a propio. U. t. c. s. ; 2. adj. Raro, singular; 3. adj. Dicho de una persona o

\footnotetext{
20 Pavarini, M (2004), Para una crítica de la ideología penal, en "Revista Antrophos. Huellas del conocimiento", n 204, Vol. "Alessandro Baratta. El pensamiento crítico y la cuestión criminal".

21 Jakobs, G.; Melia, C. (2003/4), Derecho penal del enemigo, Madrid: Cuadernos Civitas.

22 Silva Sanchez, J. (2001), La expansión del derecho penal. Madrid.
} 
de una cosa: Que es ajena a la naturaleza o condición de otra de la cual forma parte. U. t. c. s. Pedro es un extraño en su familia; 4. adj. Que no tiene parte en algo. Juan permaneció extraño A aquellas maquinaciones; y el segundo 1. adj. Dicho de un país: Que no es el propio.

El inmigrante, al ser "otro", despierta temores y odios; es "distinto", y por tanto, su exclusión de los servicios públicos, su sometimiento a medidas administrativas que son, por su naturaleza, penas; la humillación en las condiciones de acumulación humana en campos de concentración para la deportación son la cara de un nuevo binario amigo-enemigo, según la terminología Schmittiana ${ }^{23}$.

Así se observa la estrecha relación, entre extraño y extranjero, en punto a la ajenidad, en tanto no propio, ya que este no pertenece al mismo círculo de valores sociales y culturales. El extranjero, el otro, el enemigo, es en tal caso un ser que no pertenece, un bostis, y así inmigrante y enemigo devienen sinónimos para la táctica punitiva.

\section{Biopolítica, necropolítica y racismo. De la biopolítica racista a la necropolítica criminal}

Ahora bien; cabe preguntarse ¿Qué hace la política con estos "extraños"? ¿Cuáles son las herramientas y técnicas sociales mediante las cuales una comunidad acepta la existencia de seres humanos con menos derechos?

En primer lugar, para abordar estos interrogantes, es necesario recordar cuanto enseñó Foucault sobre el vínculo entre el estado y el racismo. Éste expuso de modo claro la estrecha relación que guardan los estados actuales con los estados absolutistas como implementación y continuidad del poder soberano, en tanto éste sigue manteniendo la potestad de decidir quién puede vivir y a quién debe dejar morir ${ }^{24}$.

\footnotetext{
23 Schmidt, C. (1985), El concepto de lo político. México: ediciones Folios.

24 capacidad legitimada y legitimadora de decidir sobre la vida y la muerte de los hombres y las mujeres, aglutinados ahora bajo el concepto de "población", otorgado por la idea nacionalista de homogeneidad cultural y existencial de estos.
} 
El autor destaca el carácter originario racista de la biopolítica, que se sustenta a través de avances de la ciencia y la técnica para la homogeinización social y el exterminio en cabeza del poder: un Estado, un sistema político centrado en el biopoder puede ejercer el poder de muerte o la función de la muerte, desde el momento que se introduce el racismo (el cual presenta el derecho a matar). "El racismo se inserta como mecanismo fundamental del poder en los Estados modernos (función homicida del Estado), un modo de regenerar la raza y purificarla".

Sin embargo, es Mbembe ${ }^{25}$ quien al incorporar el concepto de necropolítica explica que: "la soberanía consiste en ejercer un control sobre la mortalidad y definir la vida como el despliegue y la manifestación del poder... la soberanía que defin[e] como el derecho de matar".

Así, afirma que las formas contemporáneas de sumisión de la vida al poder de la muerte (política de la muerte) reconfiguran profundamente las relaciones entre resistencia, sacrificio y terror, y sostiene que la noción de biopoder de Foucault es insuficiente para reflejar las formas contemporáneas de sumisión de la vida al poder de la muerte (dejar morir no se equipararía a matar o sumir la vida por el poder de muerte).

El modo en que se decide respecto de quien vive y quien muere, estaría relacionado precisamente con el racismo: "por principio de raza es necesario entender también una forma espectral de división y de diferenciación humana susceptible de

\footnotetext{
25 que en modo alguno designa algo previo o posterior a la biopolítica, sino una forma de hacer y pensar que atraviesa el propio desarrollo de la modernidad, desde sus inicios, adhiriéndose de un modo paradójico y tensional a formas de corte más biopolítico. La necropolítica que enuncia Mbembe remite a una lógica de la excepcionalidad securitaria asumida por una soberanía (neo)liberal-(neo)colonial que instrumentaliza la existencia humana posibilitando la destrucción de cuerpos y sujetos considerados superfluos, siendo este carácter superfluo algo que, en gran medida, viene acompañado de un discurso que no deja de construir una noción ficcionalizada o fantasmática del enemigo. Desde ahí, la necropolítica se refiere entonces a "ese tipo de política en que la política se entiende como el trabajo de la muerte en la producción de un mundo en que se acaba con el límite de la muerte" (Mbembe, 2012: 136).
} 
ser movilizada para estigmatizar, excluir y segregar; prácticas con las que se busca aislar, eliminar, inclusive destruir físicamente a un grupo humano". Una de las claras dimensiones en la que se manifiesta esta política se refiere a la destrucción material de los cuerpos y poblaciones humanas juzgados como descartables y superfluos" (MBEMBE, 2012).

El racismo y sus concomitancias coloniales, por otra parte, dibujarán toda una apropiación del espacio que desencadena una zoologización de la vida, ya apuntada por Fanon (2001), por medio de la cual se pierde la capacidad para gestionar el "hogar", el cuerpo y con ello la posibilidad de adquirir un status político en tanto que sujeto reconocido, la vida del esclavo, del que está subsumido en una lógica racial-colonial deviene, en consecuencia, "una forma de muerte-en-la-vida" (2011 :33).

Se observa así que, a pesar de las diferencias entre unos y otros autores, todos ellos encuentran una vinculación directa entre las formas de poder y la jerarquización de seres humanos a través de una misma categoría conceptual, cual es el concepto de raza.

El racismo, sea entendido en cualquiera de los sentidos que le asignen estos autores, parece ser el motor que justifica la muerte o el derecho de dejar morir (Foucault, en el sentido en el que lo expresa cuando afirma que la génesis del estado genocida es el racismo; o bien en el de Mbembe quien directamente sostiene que esa diferenciación que se produce por el proceso de selección de personas definirá quienes deben vivir y a quienes matar, al igual que Fanon).

La forma espectral que inaugura y perpetúa el racismo estará presente de un modo determinante en las conexiones desatadas entre "lo político y el poder de matar, entre el poder y las mil maneras de matar o dejar (sobre)vivir".

Pero la hipótesis que se insinúa, sería incompleta si no incorporamos al análisis aquél concepto tan bien desarrollado por Agamben ${ }^{26}$, cual es el de la nuda vida, pues con él queda

26 Además, anticipándose a Esposito, Agamben le reprocha a Foucault no haber advertido la relación entre el modelo jurídico de ejercicio de poder y la biopolítica. De allí que concibiera 
claro que la figura del sujeto superfluo, aquel cuya fuerza de trabajo ya no es más necesaria al modo de reproducción del capital en la fase actual se convierte en portador de una vida matable, descartable, se transforma en una vida sin valor de vida, una vida indigna de ser vivida. Está fuera, es expulsable del circuito.

La nuda vida desprovista de cualquier valor de cambio, "señala el punto en que la biopolítica se convierte necesariamente en tanato-política” (AGAMBEN, 2010).

La acción política de muerte, necropolítica o tanatopolítica, según se prefiera, se imbrica como la forma política adecuada al capitalismo en crisis estructural, en el sentido de que atiende a sus objetivos. En la medida en que la "cuestión social" ya no es más soluble dentro de las instituciones sociales capitalistas, su consiguiente militarización y barbarización aparece como modelo de gestión posible (CASTILLO, 2014).

Si aceptamos lo anterior, no llamaría la atención que los países que se encuentran atravesados por el tránsito migrante y por la continuada conculcación de una vida mínimamente digna a través de prácticas que imbrican destrucción, sustracción y expulsión sean aquellos que han desarrollado mayores necropolíticas criminales.

En este sentido, a modo de ejemplo, el caso mexicano evidencia una geografía necropolítica en donde la complicidad entre soberanía y crueldad expele precariedad, represión, desapariciones y cadáveres (Villalobos Ruminott, 2016).

Afirmada la relación entre soberanía, poder, racismo y jerarquización de seres humanos, nos preguntamos entonces quiénes son, y como se llegan a permitir tales consideraciones

\footnotetext{
su propia investigación como un recurso para alumbrar ese 'punto ciego' en el campo visual del pensador francés. Pero, G. Agamben no se conformó con incorporar el modelo jurídico al tratamiento de la biopolítica desdibujando las diferencias entre ambos dispositivos, sino que, vía una operación teórica consistente en, por una parte, retomar los análisis aristotélicos que dan cuenta del carácter político del vivir humano y, por otra parte, recurrir a una figura del derecho romano arcaico como la del 'Homo Sacer', hizo coincidir este interés del poder por la vida con los orígenes mismos de la política occidental.
} 
que en gran medida se traducen en muertes de expiación sacrificial. Quiénes, de entre todos los receptores, aquellos que sufren en carne propia la necropolítica. ¿cómo es posible afirmar la descartabilidad de seres humanos? ¿Quién es el enemigo que no merece el trato de "ciudadano"?

Si consideramos lo anterior, podemos ver las vulnerabilidades que los migrantes ostentan por el hecho-siempre legítimo- de circular mundialmente en busca de mejores condiciones de vida que en sus países de orígenes, muchas veces de los que son expelidos por la violencia, la persecución ideológica, religiosa o política y también aún por búsqueda de nuevos horizontes laborales ${ }^{27}$.

La principal fuente actual de inseguridad existencial y de violencia difusa, tanto en América como en Europa, proviene de una inseguridad de la que poco llaman la atención los medios y sus empresarios morales (desempleo, desigualdad laboral, previsional; deterioro de los servicios estatales; elevación de precios; dificultades de vivienda, salud, educación).

Esa violencia difusa se expresa en actitudes xenófobas, clasistas, racistas, sexistas y en todas las formas posibles de discriminación: contra inmigrantes (Europa), contra grupos étnicos instalados desde antiguo (afroamericanos) o en crecimiento (latinos en EE. UU.), de sectores excluidos dentro de la propia sociedad (América Latina), o contra etnias minoritarias (África) ${ }^{28}$.

Es interesante el relato que solía hacer Nils Christie sobre el trato que merecían los judíos en los campos de concentración noruegos antes y después de empezar a conocer algunas

27 Unas 44.500 personas se vieron obligadas a abandonar sus casas cada día en 2017, una persona cada dos segundos, lo que sitúa la cifra de desplazados forzosos en el mundo en 68,5 millones, una récord que supone un aumento del 50\% con respecto a hace diez años, cuando eran 42,7 millones, según denuncia ACNUR. ACNUR señala que "las guerras, la violencia y la persecución han conducido a que el desplazamiento forzado alcance por quinto año consecutivo un máximo histórico". La agencia de la ONU cita la guerra en Siria, "la crisis en la República Democrática del Congo, la guerra en Sudán del Sur y la huida hacia Bangladesh de cientos de miles de rohingya desde Myanmar" como principales puntos calientes.

28 Aniyar de Castro. 
palabras del idioma. Aparentemente los campistas noruegos brindaban mejor trato a quienes podían aproximarse a su idioma o entender su cultura que a quienes no lo hacían, los que por supuesto no merecían ninguna prerrogativa graciable por parte de los concentradores.

Esto, en alguna medida, revela que parte de la tesis de Girard sobre los mitos y los estereotipos ${ }^{29}$ persecutorios $^{30}$ en los que se libera -con muerte del chivo expiatorio sacralizadoa la sociedad, tiene connotaciones y fuertes proyecciones en el plano de lo real.

Nos dice que "no es bárbaro quien habla otra lengua, sino quien confunde las únicas distinciones realmente significativas... En todas partes el vocabulario de los prejuicios tribales, nacionales, etc., no expresa el odio hacia la diferencia sino hacia su privación. No es el otro nomos lo que vemos en el otro sino la anomalía, no es la otra norma, sino la anormalidad; se convierte al inválido en deforme y al extranjero en apátrida". Es un proceso generalizador y despersonalizador que a la vez justifica la posibilidad de aniquilarlo para salvar a la sociedad.

29 ¿Cómo identificar cuando nos encontramos frente a una persecución? Girard sostiene: De la yuxtaposición de varios estereotipos en un solo e idéntico documento se deduce que hay persecución. No hace falta que aparezcan todos los estereotipos. Bastan tres de ellos y con frecuencia sólo dos. Su presencia nos lleva a afirmar que: a) las violencias son reales, b) la crisis es real, e) no se elige a las víctimas en virtud de los crímenes que se les atribuyen sino de sus rasgos victimarios, de todo lo que sugiere su afinidad culpable con la crisis, d) el sentido de la operación consiste en achacar a las víctimas la responsabilidad de esta crisis y actuar sobre ella destruyéndolas 0, por lo menos, expulsándolas de la comunidad que «contaminan».

30 Asimismo advierte: "los estereotipos de la persecución son indisociable y resulta un hecho notable que la mayoría de las lenguas no los disocien. Así ocurre en el caso del latín y del griego, por ejemplo, y, por tanto, del francés, lo que nos obliga a recurrir incesantemente, en el estudio de los estereotipos, a unos términos emparentados: crisis, crimen, criterio, critica, que provienen todos de la misma raíz, del mismo verbo griego, krino que no sólo significa juzgar, distinguir, diferenciar, sino también acusar y condenar a una víctima. No hay que confiar demasiado en las etimologías y nunca razono a partir de ellas. Pero el fenómeno es tan constante que, según creo, conviene observarlo. Sugiere una relación todavía disimulada entre las persecuciones colectivas y lo cultural en su conjunto. Si esta relación existe, ningún lingüista, ningún filósofo, ningún político la ha descubierto jamás". 
Girard nos señala que "las categorías victimarias parecen predispuestas a los crímenes indiferenciadores. Nunca se reprocha a las minorías religiosas, étnicas o nacionales su diferencia propia, se les reprocha que no difieran como es debido, y, en última instancia, que no difieran en nada. Los extranjeros son incapaces de respetar las "auténticas diferencias"; carecen de modales o de gusto, según los casos; no captan lo realmente diferencial".

Es así como el rol del mito es fundamental para comprender la persecución tanto como la categoría de lo sacrificial.

En los mitos aparece la gama completa de los signos victimarios (que serán los criminalizados). No nos damos cuenta porque consideramos fundamentalmente la pertenencia de las víctimas a una minoría étnica o religiosa conocida. Ese rasgo no puede reaparecer sin más en la mitología. Pero tenemos su equivalencia en un tema que desempeña un papel central en todas las partes del mundo, el del extranjero colectivamente expulsado o asesinado.

La victima (siempre presentada como victimario) es un hombre que viene de fuera, un extranjero significado. Se le invita a una situación que termina con su linchamiento. ¿Por qué? Ha hecho algo que no debía hacer; se ve su comportamiento como funesto; uno de sus gestos es mal interpretado. También en este caso basta con suponer una víctima real, un extranjero real, y todo se aclara. Si el extranjero se comporta de manera extraña o insultante a ojos de sus anfitriones, es porque obedece a unas normas extranjeras. Más allá de un cierto punto de etnocentrismo, el extranjero pasa a ser típicamente mitológico, tanto para lo mejor como para lo peor. El menor malentendido puede acabar mal. La víctima es un chivo expiatorio.

Chivo expiatorio denota simultáneamente la inocencia de las víctimas, la polarización colectiva que se produce contra ellas y la finalidad colectiva de esta polarización. Los perseguidores se encierran en la "lógica" de la representación persecutoria y jamás pueden salir de ella. 
Esta hipótesis, en efecto, resuelve según el mismo autor, el enigma fundamental de cualquier mitología: el orden ausente o comprometido por el chivo expiatorio se restablece o se establece por obra de aquel que fue el primero en turbarlo. Es concebible que una víctima aparezca como responsable de las desdichas públicas, y esta misma víctima devuelva el orden, lo simboliza e incluso lo encarna.

De ello se desprende que los procesos mediante los cuales socialmente se busca expiar los males sociales recepta en la criminalización tanto como en la victimización rasgos propios estereotipados que responden a mitos o prejuicios sociales altamente internalizados, lo que refuerza aún más las etiquetas sociales, en especial las negativas, que son reorganizadas rápidamente por el sistema penal en el mecanismo de selección.

\section{La reproducción simbólica de la violencia racista a través de la comunicación mediática}

La reproducción y persecución estereotipada que construye el ellos, se nutre de datos reales e imaginarios que son fomentados y estimulados a través de los medios de comunicación ${ }^{31}$.

La exacerbación de una opinión pública sobreexcitada, la utilización del slogan desprovisto de contenido pensante que se orienta a sensibilizar a través de imágenes y músicas trágicas, hacen del discurso mediático comunicacional una de las herramientas eficaces y poderosa del poder punitivo real. Por ello, constituyen en sí una criminología en tanto discurso y acción sobre la cuestión penal, que en la actualidad confirma un discurso legitimador al que cabe prestar particular atención.

La mass media produce o reproduce en muchos casos las miradas segmentadas que atraviesan la realidad, configurando un sesgo parcial y prejuicioso que sostiene la construcción de un ellos, que se torna conveniente cuando es configurada por los medios masivos de comunicación monopolizados (en

31 Sobre la televisión: Bourdieu, P (1997) Sobre la Televisión. Barcelona: Anagrama. 
particular la televisión, en manos de conglomerados que forman parte del mismo capital trasnacionalizado), y de los políticos útiles, confiando en que la población general reaccionará a ello ${ }^{32}$.

Zaffaroni nos llama la atención sobre la necesidad de analizar de un modo más preciso el rol que juegan los medios masivos de comunicación a fin de evitar futuras masacres. La llamada criminología mediática (Zaffaroni:2013) creará una realidad a través de la información, subinformación y desinformación en convergencia con prejuicios y creencias basados en una etiología criminal simplista pero asentada en una causalidad mágica.

La realidad para esta criminología es la existencia de un mundo de personas decentes frente a una masa de criminales identificada a través de estereotipos, que configuran un "ellos" separado del resto de la sociedad. La particularidad que presenta es que ese ellos no se compone sólo de delincuentes, sino del mundo más amplio de estereotipados que son parecidos, pero que no han cometido ningún delito y que nunca lo han de cometer. El mensaje de la criminología mediática actual es que el -entre otros- el inmigrante viene por el trabajo de la sociedad decente, que acechará los hogares con su cultura diversa y su idioma comprometerá los valores culturales más esenciales de la occidentalidad.

Sin embargo, cabe preguntar ¿qué oculta el discurso de los medios masivos de comunicación?

Oculta las muertes masacradoras, omite así como hizo la criminología que denominamos "tradicional" las muertes producidas por los propios estados y sus brazos ejecutores: los sistemas penales. Evita enunciar las muertes o las disfraza, las oculta visibilizando como inseguridad tan sólo aquellos delitos individuales que producen el efecto reproductor de las propias acciones genocidas.

\footnotetext{
32 A mayor abundamiento: Sartori, G. (1998) Homo videns: la sociedad teledirigida. Barcelona. Samar, R. (2007) El medio es violencia. Cultura, comunicación y construcción de la realidad. Neuquén. También Zaffaroni en "Democracia y tecnología comunicacional” en: http://lateclaenerevista.com/2018/04/10/democracia-tecnologia-comunicacional-e-raul-zaffaroni/.
} 
Por ello, una de las características más salientes de la criminología mediática (o la palabra de los medios) es que naturaliza las muertes - las normaliza por la prensa y la televisión-, pues todos los efectos letales del sistema penal son para ella un producto natural (inevitable) de la violencia propia del ellos. Y llegan al máximo encubrimiento en los casos de ejecuciones sin proceso disfrazadas de muertes en enfrentamientos cuando éstos son presentadas como episodios de la guerra contra el crimen, en los que se muestra el cadáver del fusilado como el de un soldado muerto en la guerra, como signo de eficacia preventiva (Zaffaroni:2009).

\section{A modo de síntesis}

Hasta aquí hemos afirmado algunas de las características esenciales que se reiteran en la elaboración realizadora de la negación del ser "humano" para degradarlo a un "ser sin ser", una "nuda vida" que, sostenida sobre la base racista, se manifiestan de la siguiente manera:

- Se cimenta sobre prejuicios estereotipados muchas veces basados en la selección mítica (Girard) o de contenido racista (Foucault/Mbembe/Fanon)

- Se designa al ajeno como un "otro": el otro es el diferente. Se la da la característica de alter (alteridad)

- Se le asigna, a través del mecanismo justificador persecutorio, un carácter "delictual" que refuerza el ser rechazado socialmente

- La definición del otro, el diferente, se identifica con la de "enemigo"33

33 Lola Aniyar de Castro sostenía que los sujetos considerados enemigos, son "no personas", "no ciudadanos": la desvalorización previa de la víctima es una constante en la literatura criminológica, algo que ya habían tomado en cuenta algunos psicólogos y criminólogos clínicos al analizar los procesos motivacionales de los delincuentes. Fue incluso tema predilecto de la literatura (recuérdese el ejemplo del Raskolnikof de Dostoievski en Crimen y Castigo, y todas las explicaciones que construye para considerar que su víctima merece morir).

Las víctimas, en ambos casos, se consideran sujetos fungibles, indeterminados, contingentes: cualquiera que reúna las características que configuran al enemigo a destruir 0 al 
- El concepto de enemigo político y la posible situación bélica legitiman la negación de condición de persona,

- Los medios masivos de comunicación exacerban a través del discurso sensibilizador y de slogans la reproducción de estereotipos

- La mass media utiliza el lenguaje bélico de la guerra para abordar algunas "inseguridades" en detrimento de otras

- La imagen del criminalizado como el enemigo se refuerza a través de su visibilización como delincuente antes que como víctima estereotipada

- Se lo asemeja a un ser humano indeseable, descartable, innecesario que ofende al cuerpo social

- Se lo degrada a nuda vida ya sea mediante estigmatización social, la segregación o el exterminio

- La disposición de los cuerpos ya no aparece para la vida sino para la muerte

- La muerte civil se traduce en muerte real

- Se desarrolla la política masacradora/genocida

Estas líneas, en definitiva, ponen de manifiesto una fuerte vinculación entre los avances del estado de policía y el tratamiento de personas desprendidas de su calidad de tal con una fuerte justificación racista que alienta o germina una masacre (Zaffaroni:2013).

\section{El poder punitivo es masacrador}

La criminalización y segregación de los migrantes a través del sistema penal, en el viejo y nuevo continente caracterizan la política criminal actual en la era de la globalización.

Las dinámicas racistas y su consecuente rechazo y expulsión son, en definitiva, una generadora en la era actual de masacres 
por goteo que cada vez más se presentan como parte de la necro política criminal.

Estas relaciones son claras si se observa el modo en que han sido justificadas a través de los discursos y del ejercicio del poder punitivo a lo largo de la historia.

El estado racista garantiza la política de la muerte y engendra de esa manera un estado genocida que, no requiere ya de excpecionalidad, sino que se realiza a través de los mecanismos disciplinadores y configuradores que funcionan dentro del sistema penal formal, proyectándose hacia la masacre.

En la actualidad, la muerte real y el trato degradante a los inmigrantes se manifiesta en los procesos de expulsión y exclusión de los migrantes, la normativización delictual de la sola presencia considerada como ilegal, pero sobre todo y en especial con las omisiones de prestar auxilio a refugiados, asilados o balseros, no asistir en situaciones humanitarias en las que se arriba a las fronteras, separando a padres e hijos (extranjeros o nativos), expulsar a los niños de inmigrantes ilegales nacidos en países que no aceptan a sus padres por la condición de ilegal, etc.

No asistir se convierte en hacer morir, ya no más la política y el poder se manifiesta como el control de los cuerpos vivos, sino antes bien, en control sobre la vida y la muerte de aquellos que, como en la inmigración -no toda sino la que por contenido racista suele descartarse o considerarse "peligrosa"- se consideran seres humanos sin derechos..."se consideran menos que seres humanos."

Estos mecanismos no son más que hacer sufrir por acción u omisión, dejar morir o simplemente matar. Nuevamente el inicio de nuestra presentación se hace presente: el racismo y la necropolítica se vuelven a poner de manifiesto, lo que nos permite afirmar que la situación actual de los migrantes se presenta, en el mundo globalizado/tardo-colonialista como una masacre larvada o por goteo.

Recordemos que tal como se dijo, en la teoría política el tratamiento diferenciado de seres humanos privados del carácter 
de personas (enemigos de la sociedad) es propio del estado absoluto, que por su esencia no admite grados, y, por ende, resulta incompatible con la teoría política del estado de derecho. Con esto se introduce una contradicción permanente entre la doctrina jurídico penal que admite y legitima el concepto de enemigo y los principios constitucionales e internacionales del estado de derecho, o sea, con la teoría política de este último.

La preocupación por las muertes del sistema penal y la necesidad de prevenirlas ha sido presentada en el campo de la criminología por Zaffaroni en su propuesta de criminología cautelar preventiva, al analizar el fenómeno de las masacres del poder punitivo del que venimos hablando.

A qué se refiere cuando propugna una criminología cautelar (o preventiva de masacres). La primera advertencia que este autor reitera es que la incorporación de la masacre en la Criminología, tanto teórica como de campo, no puede dejar de asumir el mencionado compromiso ideológico-político con los derechos humanos (en especial el de la vida). Así, una criminología que incorpore a la masacre debe dejar de ser neutral para pasar a afrontar un compromiso ideológico abierto frente a la plurifactorialidad masacradora.

Por tal motivo, la tarea de los criminólogos latinoamericanos consistirá en investigar cómo funciona la dinámica de esta criminología en nuestros marcos políticos generales, y deducir algunas constantes, a su vez que solventará una respuesta contra-punitiva sobre la base de la investigación del campo.

Para ello, es necesaria, como toda posición crítica que señale y evidencie la demagogia de que se valen para profundizar los prejuicios discriminadores populares que culminan en lo sacrificial. Si la criminología mediática sintetiza en sus estereotipos los peores prejuicios discriminantes de cada sociedad, los manipula y acentúa para crear un ellos de enemigos, es tarea del criminólogo crítico desbaratar aquél mecanismo, con un carácter militante que incluya todos los ámbitos comunicacionales, para contrarrestar al Homo videns con el homo sapiens, lo que 
-nuevamente- nos obliga a repensar todo el sistema penal no sólo en el plano estrictamente jurídico y realizador de un derecho al servicio de los hombres y mujeres y no del estado, sino también desde una perspectiva criminológica de prevención, que nos haga advertir sobre las trampas del poder punitivo $\mathrm{y}$ nos invite a militar activamente hacia una criminología de los derechos humanos. 